\title{
Lung accumulations of eosinophil granulocytes after exposure to cornstarch glove powder
}

\author{
J. Grunewald*, A. Eklund*, K. Katchar*, A. Moshfegh", C. Lidén", L. Lundgren+ ${ }^{+}$, L. Skaređ, \\ G. Tornling*,\$
}

Lung accumulations of eosinophil granulocytes after exposure to cornstarch glove powder. J. Grunewald, A. Eklund, K. Katchar, A. Moshfegh, C. Lidén, L. Lundgren, L. Skare, G. Tornling. (C) ERS Journals Ltd 2003.

ABSTRACT: Starch is a main component of wheat flour, which, besides being an occupational allergen can also induce irritative symptoms in the airways. A purified starch product (cornstarch glove powder) was used to investigate whether starch alone could induce airway inflammation. The aim of the study was to investigate a role for starch in wheat flour-induced airway inflammation.

Ten healthy individuals were exposed to cornstarch glove powder in a whole-body exposure chamber. Bronchoscopy with bronchoalveolar lavage (BAL) was performed 2-3 weeks before and 1 day after exposure, and the BAL cells were counted differentially. In addition, the expression of activation, adhesion and subset markers on alveolar macrophages and BAL T-cells were investigated using flow cytometry.

A three-fold increase in BAL cell concentrations was found, with a selective accumulation and activation of eosinophilic granulocytes, as well as an influx of nonactivated monocytes and polyclonal CD4 + T-cells into the airways.

The results show that inhalation of cornstarch glove powder leads to the development of a subclinical inflammation in the airways, with an accumulation of eosinophilic granulocytes. The authors suggest that such exposure may be an interesting model for studying factors contributing to lung accumulations of eosinophil granulocytes in humans. Eur Respir J 2003; 21: 646-651.
Divisions of * Respiratory Medicine, ${ }^{\#}$ Clinical Immunology and Allergy, Dept of Medicine, Karolinska Hospital and Institutet, Occupational and Environmental Dermatology, Dept of Medicine, Karolinska Institutet and Stockholm County Council, ${ }^{+}$Workplace Air, National Institute for Working Life and ITM, Stockholm University, Stockholm, and ${ }^{\S}$ Clinical Science, Astra Zeneca, Lund, Sweden.

Correspondence: J. Grunewald, Dept of Medicine, Lung Research Laboratory L2:01, Karolinska Hospital, S-171 76 Stockholm, Sweden. Fax: 46851775451

E-mail: johan.grunewald@medks.ki.se

Keywords: Bronchoalveolar lavage, cornstarch glove powder, eosinophil granulocytes

Received: March 252002

Accepted after revision: November 292002

This study was supported by the Swedish Council for Work Life Research (RALF), the Swedish Heart-Lung Foundation, the King Oscar II Jubilee Foundation, the Swedish Foundation for Health Care Sciences and Allergy Research and Karolinska Institutet.
Wheat flour is an occupational allergen related to an increased risk of developing chronic airway symptoms (baker's asthma) [1]. The authors have previously registered signs of airway inflammation in healthy individuals exposed to wheat flour (unpublished data) in a whole-body exposure chamber [2]. It is not known to what extent wheat flour components other than proteins, such as starch, may contribute to the induction of airway inflammation. Close to one-third of bakers with asthma and/or rhinitis did not have immunoglobulin (Ig)E antibodies specific to any of the bakery allergens [1]. Following exposure to cornstarch particles from starchpowdered gloves, used in surgical procedures, a granulomatous inflammation of peritoneal surfaces was described [3, 4]. Starch also functions as a carrier of latex particles, for example, and starch-powdered gloves could induce an IgE-mediated asthmatic response in latex-sensitised individuals [5, 6].

The aim of this study was to investigate whether starch alone could induce alterations in inflammatory parameters in the airways. Ten healthy individuals were exposed to an airborne total dust concentration of $5.9 \mathrm{mg} \cdot \mathrm{m}^{-3}$ (median) cornstarch glove powder for $1 \mathrm{~h}$, using a whole-body exposure chamber [2]. Cells were obtained from the lungs through bronchoscopy with bronchoalveolar lavage (BAL) 2-3 weeks before and 1 day after exposure. Differential counts were performed on BAL cells, and flow cytometry analysis of the expression of adhesion, activation and subset markers on alveolar macrophages (AM) and T-cells was carried out. The results indicate that cornstarch glove powder induces an accumulation of activated eosinophils into the alveoli, together with an influx of AM and T-cells, but without clinical signs of airway symptoms.

\section{Material and methods}

\section{Subjects}

Ten healthy individuals (five males, five females, aged 18-49 yrs (median 26 yrs)) were included in the study. None of these individuals had a history of atopy, and they all had normal serum $\operatorname{IgE}$ values $\left(<120 \mathrm{U} \cdot \mathrm{L}^{-1}\right)$ as well as normal radioallergosorbent tests specific for corn starch. All individuals were nonsmokers and all had normal chest radiographs and were without signs of any respiratory infection 1 month before and at the time of the study. Informed consent was obtained and the local ethics committee approved the study.

\section{Study design}

Each individual was exposed to cornstarch glove powder (Absorbo ${ }^{\mathrm{TM}}$; National Starch and Chemical Corporation, 
Bridgewater, NJ, USA) for $1 \mathrm{~h}$ in the whole-body exposure chamber. Cornstarch glove powder is an absorbable powder prepared by processing cornstarch in accordance with the requirements of the US Pharmacopeia Monographs on Absorbable Dusting Powder as well as the British Pharmacopeia Monographs on Steralisable Maize Starch. It was tested by low-temperature ashing and found to contain 96-98\% organic materials, i.e. corn starch, and magnesium oxide $(\mathrm{MgO})$. No endotoxins could be detected in the powder (Multi-test Limulus Amebocyte Lysate; BioWhittaker, Walkersville, MD, USA). Total dust was sampled in $37 \mathrm{~mm}$ open-faced cassettes on membrane filters made of mixed esters of cellulose (poresize $0.8 \mu \mathrm{m}$ ) at flow rate $2 \mathrm{~L} \cdot \mathrm{min}^{-1}$. Respirable dust (small airborne particles that can penetrate into the gas-exchange regions of the human lung) was sampled with cyclones (Casella SIMPEDS; Casella London Ltd, London, UK) on membrane filters made of mixed esters of cellulose (pore-size $8 \mu \mathrm{m})$ at $1.9 \mathrm{~L} \cdot \mathrm{min}^{-1}$.

Peripheral blood and BAL samples were obtained 2-3 weeks before and 1 day after the dust exposure. In addition, a third (follow-up) bronchoscopy with BAL was performed 7-8 months after the cornstarch glove powder exposure in the four individuals (subject nos 4, 6, 7 and 9) exhibiting the most pronounced accumulation of lung eosinophils.

\section{Bronchoalveolar lavage and handling of cells}

Bronchoscopy with BAL was performed as described previously [7]. Briefly, BAL fluid was retrieved by instilling five aliquots of $50 \mathrm{~mL}$ sterile phoshate-buffered saline (PBS) solution at $37^{\circ} \mathrm{C}$ in a middle lobe bronchus. After each instillation, the fluid was gently aspirated and collected in a siliconised bottle kept on ice. Mean recovery was 75\% (interquartile range $69-82 \%$ ) at the first and $72 \%(68-82 \%)$ at the second BAL.

The BAL fluid was strained through a double layer of Dacron nets (Millipore, Bedford, Ireland) centrifuged at $400 \times g$ for $10 \mathrm{~min}$ at $4^{\circ} \mathrm{C}$ and the cells were resuspended in Roswell Park Memorial Institute (RPMI) 1640 (Sigma Aldrich Co., St Louis, MO, USA). The BAL fluid cells were counted in a Bürker chamber and cell viability was determined by Trypan blue exclusion as $93 \%(91-95 \%)$ at the first and $92 \%(90-94 \%)$ at the second BAL. For differential cell counts, cytospins were prepared by cytocentrifugation at $20 \times g$ for $3 \mathrm{~min}$ and stained in May-Grünwald Giemsa. Peripheral blood lymphocytes were separated from heparinised peripheral blood by Ficoll-Hypaque (Amersham Pharmacia Biotech, Uppsala, Sweden) gradient centrifugation, washed twice and diluted in RPMI 1640.

\section{Immunostaining and flow cytometry}

Immunolabelling of alveolar macrophages was performed using primary nonconjugated monoclonal antibodies (Mab) specific for CD11b (CR-3), CD14 (lipopolysaccharide receptor), CD16 (Fc $\gamma$ RIII), CD54 (intercellular adhesion molecule-1), CD86 (costimulatory marker) and human leukocyte antigen (HLA) class I and II (activation markers), followed by a secondary Rhodophyta phycoerythrin (RPE)-conjugated Mab. Antibodies with isotype-matched controls were obtained from DAKO (Glostrup, Denmark).

BAL and peripheral blood CD4+ and CD8+ T-lymphocytes were detected using RPE-Cy5 conjugated CD4, RPE-conjugated CD8 and fluorescein isothiocyanate (FITC)-conjugated CD3 $\mathrm{Mab}$ (DAKO). Triple staining of cells was performed to determine the expression of activation markers by CD4+ and
CD8+ cells, respectively, and to assess the percentage of CD3+ cells that expressed CD4 and CD8. FITC-labelled Mab specific for CD25 (interleukin-2R, early activation; DAKO), CD26 (activation, costimulation; Pharmingen, La Jolla, CA, USA), CD28 (costimulation; Coulter Immunotech, Marseille, France), CD57 (subset marker; Becton Dickinson, San José, CA, USA), CD69 (very early activation; Becton Dickinson) and HLA-DR (late activation; Becton Dickinson) were used. After antiserum incubations and washings, cells were fixed in PBS with $1 \%$ formaldehyde. The samples were analysed in a flow cytometer (FACSort; Becton Dickinson). The cell populations were identified and gated by forward- and side-light scattering properties. For AMs, the quantitative level of expression of each antigen (mean fluorescence intensity) was determined after subtraction of the background fluorescence intensity levels. For lymphocytes, the percentages of positively labelled cells in the CD4+ and CD8+ subsets were determined, respectively. Isotype-matched negative control antibodies always stained $<1 \%$ of CD $4+$ and CD $8+$ lymphocytes.

\section{Bronchoalveolar lavage fluid analyses}

BAL fluid eosinophil cationic protein (ECP) and tryptase were analysed using commercially available fluoroimmunoassays (Pharmacia Diagnostics AB and Pharmacia \& Upjohn, Uppsala, Sweden). ECP values $<2 \mu \mathrm{g} \cdot \mathrm{L}^{-1}$ and tryptase levels $<1 \mu \mathrm{g} \cdot \mathrm{L}^{-1}$ were considered negative. Eotaxin levels in BAL fluid were measured by enzyme-linked immunosorbent assay according to the manufacturer's description (Quantikine; R\&D Systems, Minneapolis, MN, USA).

\section{Statistical analysis}

The data are presented as medians with lower and upper quartile values (P25-P75) unless otherwise stated. For intraindividual comparisons of data retrieved before and after allergen challenge, Wilcoxon's signed-rank test was used. Correlations were calculated using the Spearman R test.

\section{Results}

\section{Cornstarch glove powder exposure}

The total dust concentration of cornstarch glove powder measured on both sides close to the breathing zone of the subject was $5.9 \mathrm{mg} \cdot \mathrm{m}^{-3}$ (interquartile range $5.5-6.2$ ), and the concentration of respirable dust was $0.62 \mathrm{mg} \cdot \mathrm{m}^{-3}(0.60-0.67)$. The airborne respirable dust was found to contain $\sim 40 \%$ organic material, i.e. cornstarch, while the remaining fraction was $\mathrm{MgO}$.

\section{Bronchoalveolar lavage fluid cell counts}

BAL fluid cells were retrieved and counted from all individuals before and after cornstarch glove powder exposure (table 1). The exposure resulted in a three-fold increase in BAL total cell concentrations, from 84.2 to $241.3 \times 10^{6}$ cells $\cdot \mathrm{L}^{-1}$ (fig. 1a and table 1). There was a significant increase in concentrations of AM, lymphocytes and eosinophils, as well as a strong tendency for mast cells, while neutrophils did not change. Analysing relative numbers showed, however, that the only cells with a significant increase were the eosinophils (fig. 1b), while macrophages were found to decrease significantly (table 1). Four individuals (subject nos 4, 6, 7 and 9) were evaluated at a third occasion, 7-8 months after the dust 
Table 1. - Differential counts of bronchoalveolar lavage (BAL) fluid cells retrieved from 10 healthy individuals 2-3 weeks before and 1 day after exposure to cornstarch

\begin{tabular}{lcc}
\hline & Before & After \\
\hline Total cells $\times 10^{6}$ & $15.9(12.8-20.4)$ & $39.4(36.6-47.1)^{* *}$ \\
Concentrations $\times 10^{6} \mathrm{~L}^{-1}$ & & \\
All BAL fluid cells & $84.2(70.3-122.6)$ & $241.3(184.4-247.3)^{* *}$ \\
Macrophages & $78.1(64.9-114.5)$ & $177.8(157.2-200.2)^{* *}$ \\
Lymphocytes & $5.4(2.5-7.1)$ & $11.2(8.7-14.0)^{* *}$ \\
Neutrophils & $0.7(0.5-1.3)$ & $1.0(0.5-1.8)$ \\
Eosinophils & $0.0(0.0-0.2)$ & $10.1(8.1-50.0)^{* *}$ \\
Mast cells & $1.5(0.0-5.0)$ & $3.5(2.0-30.0)^{*}$ \\
Relative percentage & & \\
of cells & & \\
Macrophages & $92.7(89.2-95.4)$ & $87.1(77.4-91.0)^{* *}$ \\
Lymphocytes & $6.7(3.6-8.0)$ & $5.3(4.2-6.2)$ \\
Neutrophils & $0.8(0.4-1.6)$ & $0.4(0.2-1.0)$ \\
Eosinophils & $0.0(0.0-0.2)$ & $4.7(4.2-20.2)^{* *}$ \\
\hline
\end{tabular}

Data are presented as median value (interquartile range). ${ }^{\#}$ : cells in 10 visual fields, magnification $\times 160$; NS: nonsignificant. *: $\mathrm{p}<0.05 ; * *: \mathrm{p}<0.01$.

exposure. At that point, BAL fluid cells were close to the original pre-exposure levels, with relative numbers of eosinophils being $0.4,0.4,0$ and $0.2 \%$, respectively (fig. $1 \mathrm{~b}$ ).
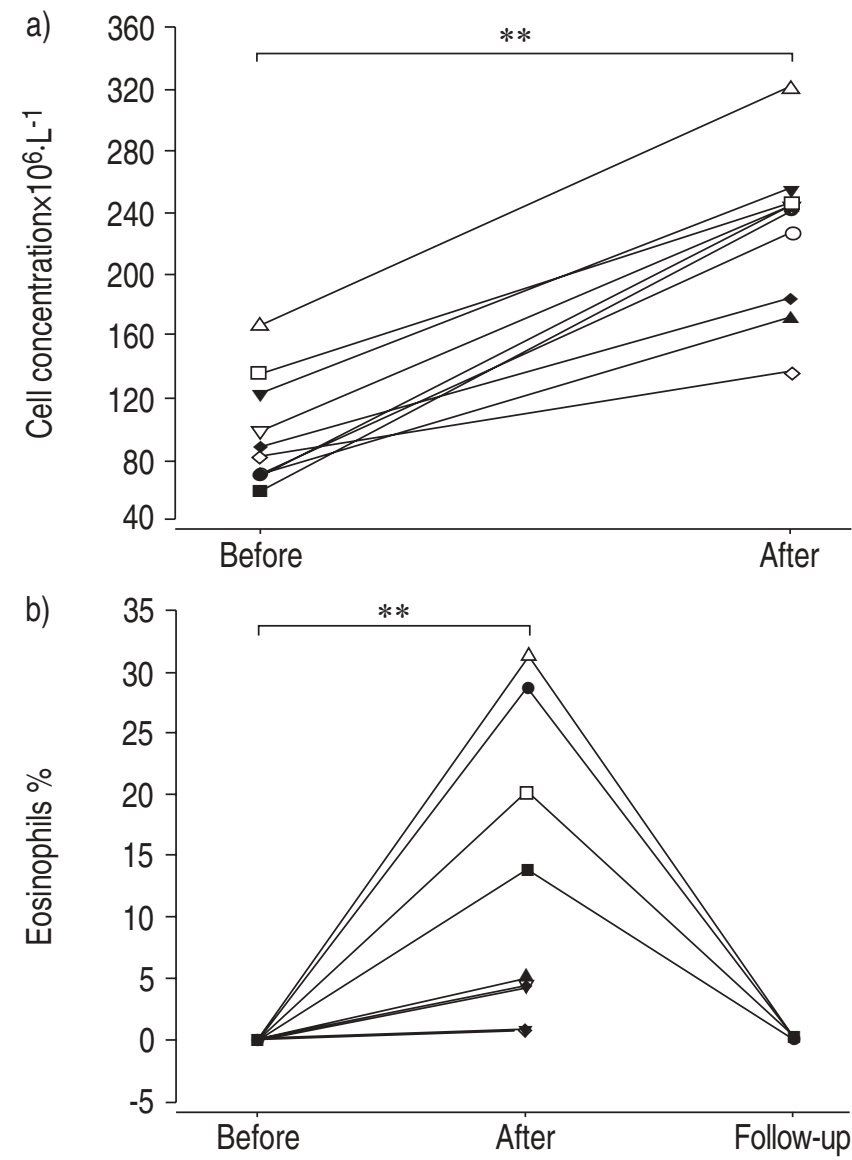

Fig. 1.-a) Bronchoalveolar lavage cell concentrations $\left(\times 10^{6} \mathrm{~L}^{-1}\right)$ before and after cornstarch glove powder exposure in 10 healthy individuals and b) relative numbers $(\%)$ of eosinophil granulocytes 2-3 weeks before $(n=10), 1$ day after $(n=10)$ and at follow-up 7-8 months after $(\mathrm{n}=4)$ exposure. Subject nos: $\bullet: 1 ; \nabla: 2 ; \bigcirc: 3 ; \triangle: 4$; $\mathbf{\Delta}: 5 ; \square: 6 ; \mathbf{\square}: 7 ; \nabla: 8 ; 0: 9 ; \diamond: 10 . * *: \mathrm{p}<0.01$.
ECP in BAL fluid was not detectable before dust exposure $\left(<2 \mu \mathrm{g} \cdot \mathrm{mL}^{-1}\right.$ in all individuals), while after exposure four individuals (subject nos 4, 6, 8 and 9) had elevated values $(14,0,5.2,2.2$ and 4.0, respectively). The postexposure ECP values in BAL fluid correlated significantly with the postexposure relative numbers of BAL eosinophils $(\mathrm{p}=0.01$; fig. 2). Tryptase was not detected in BAL fluid, either before or after exposure. The eotaxin levels in BAL fluid were similar before $\left(42.7,41.3-43.6 \mathrm{pg} \cdot \mathrm{mL}^{-1}\right)$ and after exposure $(41.3$, $\left.40.5-44.4 \mathrm{pg} \cdot \mathrm{mL}^{-1}\right)$.

\section{Alveolar macrophage phenotype}

The AM expression of adhesion, activation and subset markers was investigated in BAL fluid retrieved before and after dust exposure, and in addition in four individuals 7-8 months after exposure (table 2). The most distinct changes were noted for the lipopolysaccharide receptor, CD14, which was expressed more significantly by the AMs after exposure $(p<0.01$; fig. 3a), and for the Fc $\gamma$-receptor CD16, with a significantly reduced expression after exposure ( $p=0.01$; fig. $3 b$ ). As can be noted in figure 3, the expression of CD14 and CD16 tended to return to close to pre-exposure values when analysed again 7-8 months after exposure. Both activation markers HLA class I and II were significantly reduced following exposure (table 2). Markers for cell adhesion (CD11

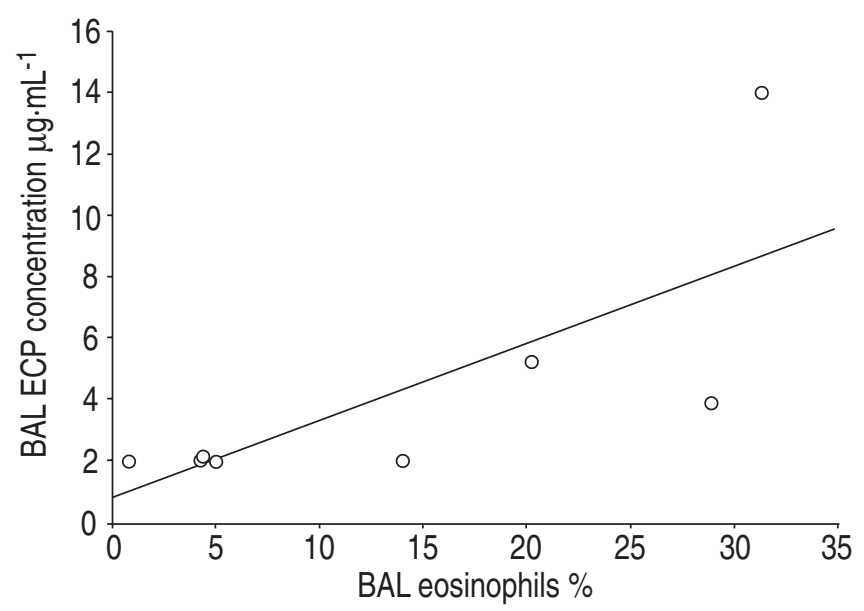

Fig. 2.-Correlation between relative numbers of eosinophil granulocytes and eosinophil cationic protein (ECP) 1 day after exposure to cornstarch glove powder. BAL: bronchoalveolar lavage.

Table 2.-Expression of surface markers by alveolar macrophages from 10 individuals 2-3 weeks before and 1day after exposure to corn dust

\begin{tabular}{lccc}
\hline & Before & After & p-value \\
\hline CD11 & $172(64-229)$ & $114(90-140)$ & NS \\
CD14 & $57(41-66)$ & $101(90-110)$ & $<0.01$ \\
CD16 & $231(211-268)$ & $155(126-183)$ & $<0.01$ \\
CD54 & $70(42-78)$ & $79(58-86)$ & NS \\
CD86 & $89(78-98)$ & $71(60-79)$ & NS \\
HLA class I & $1452(1432-1759)$ & $835(664-1056)$ & $<0.05$ \\
HLA class II & $2030(1805-2202)$ & $1009(753-1539)$ & $<0.05$ \\
\hline
\end{tabular}

Data are presented as median value (interquartile range). Values show mean fluorescence intensity levels for each marker. HLA: human leukocyte antigen. NS: nonsignificant. 

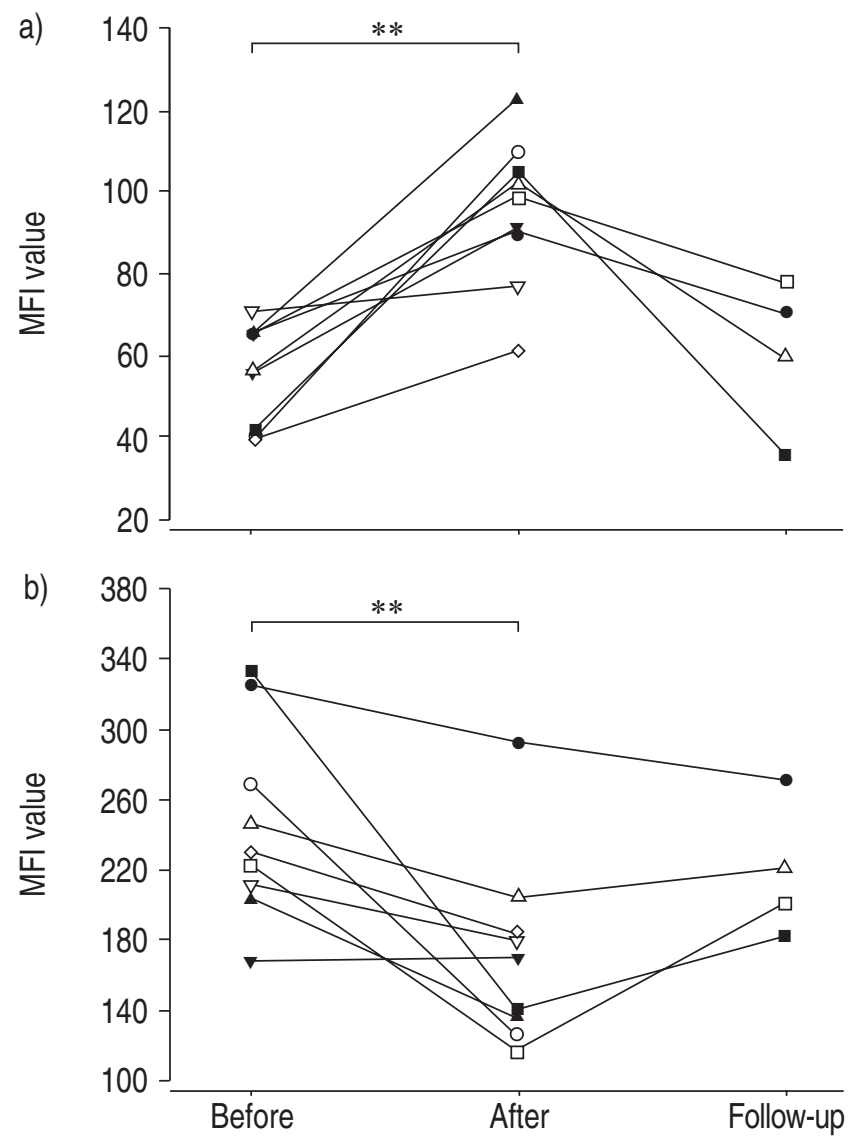

Fig. 3. - Alveolar macrophages (AM) expression of a) CD14 or b) CD16 2-3 weeks before, 1 day after and at follow-up 7-8 months after exposure for cornstarch glove powder. AM expression is shown as mean fluorescence intensity (MFI). Subject nos: $\nabla: 2 ; \bigcirc: 3 ; \triangle: 4$; $\boldsymbol{\Lambda}: 5 ; \square: 6 ; \mathbf{\square}: 7 ; \nabla: 8 ; \bullet: 9 ; \diamond: 10 .{ }^{* *}: \mathrm{p}<0.01$.

and CD54) and costimulation (CD86) showed no significant changes (table 2).

\section{Lymphocyte phenotype}

Following starch exposure, the BAL CD4/CD8 ratio increased from 1.4 to 3.4 (NS), indicating an influx of CD4+ T-cells into the alveoli. A careful phenotypic characterisation of CD4+ and CD8+ lymphocyte subsets in BAL fluid as well as in peripheral blood was performed before and after dust exposure (table 3). The most significant changes were found in the CD4+ BAL T-cell subset, where the number of cells

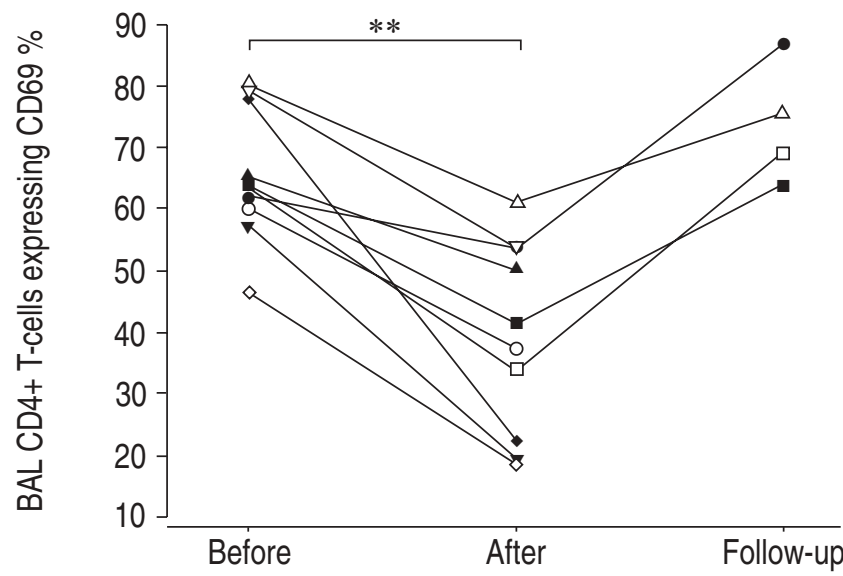

Fig. 4. - The relative numbers of $\mathrm{CD} 4+$ bronchoalveolar lavage (BAL) T-cells expressing CD69 2-3 weeks before, 1 day after and at follow-up 7-8 months after exposure for cornstarch glove powder. Subject nos: $\diamond: 1 ; \nabla: 2 ; \bigcirc: 3 ; \triangle: 4 ; \boldsymbol{\Lambda}: 5 ; \square: 6 ; \mathbf{\square}: 7 ; \nabla: 8 ; \bullet: 9$; $\diamond: 10 . * *: \mathrm{p}<0.01$.

expressing an early activation marker (CD69, $\mathrm{p}<0.01$; fig. 4), a late activation marker (HLA-DR, $\mathrm{p}<0.05$ ) and a subset marker (CD57, $\mathrm{p}=0.01$ ) significantly decreased. Conversely, CD4+ BAL T-cells expressing the costimulatory molecule $\mathrm{CD} 28$, increased significantly $(\mathrm{p}<0.05)$. Another early activation marker, CD25, tended to be expressed by more CD4+ BAL T-cells after exposure, while the number of cells expressing the activation marker CD26 was unchanged (table 3).

Similar to BAL CD4+ T-cells, the number of BAL CD8+ T-cells expressing CD69 was also significantly decreased after dust exposure (table 3). In the BAL CD8+ T-cell subset, the only other significant change was an increased number of T-cells expressing the activation marker CD26. The same marker was expressed by significantly more peripheral blood CD4+ T-cells $(\mathrm{p}<0.05)$ as well as CD8+ T-cells $(\mathrm{p}<0.05)$ after dust exposure, while all other markers (CD25, CD28, CD57, CD69 and HLA-DR) were unchanged in both (CD4+ and CD8+) peripheral blood T-cell subsets.

To investigate any accumulation of antigen-specific T-cells to the lungs, the relative numbers of T-cell receptor AV2S3, BV2 and BV8 expressing T-cells in the CD4+ and CD8+ BAL and peripheral blood T-cell subsets, respectively, were evaluated in three individuals (subject nos 8, 9 and 10). In general, only minor changes were noted in each subset. The most pronounced change was found in individual 9, who had a CD4+ BAL T-cell expansion expressing BV2 and making up $34.0 \%$ of all CD4+ BAL T-cells. This T-cell expansion was reduced to $22.8 \%$ following dust exposure, in line with an

Table 3. - Phenotyping of CD4+ and CD8+ bronchoalveolar lavage (BAL) lymphocytes retrieved 2-3 weeks before and 1 day after exposure to cornstarch glove powder

\begin{tabular}{|c|c|c|c|c|c|c|}
\hline & \multicolumn{3}{|c|}{ CD4+ BAL T-cells } & \multicolumn{3}{|c|}{ CD8+ BAL T-cells } \\
\hline & Before & After & p-value & Before & After & p-value \\
\hline $\mathrm{CD} 25$ & $6.9(4.1-8.7)$ & $16.4(10.2-21.4)$ & 0.35 & $0.6(0.1-3.4)$ & $0.8(0.4-1.5)$ & 0.60 \\
\hline $\mathrm{CD} 26$ & $68.1(62.4-75.7)$ & $71.4(60.0-73.3)$ & 0.87 & $46.2(36.6-56.3)$ & $60.5(50.5-77.5)$ & 0.04 \\
\hline CD28 & $84.5(76.5-89.4)$ & $93.2(89.9-98.1)$ & 0.02 & $44.4(31.6-48.7)$ & $63.6(43.5-70.7)$ & 0.11 \\
\hline CD57 & $24.7(17.3-27.2)$ & $12.4(5.0-16.6)$ & 0.01 & $16.5(8.8-22.7)$ & $17.7(6.6-21.0)$ & 0.51 \\
\hline CD69 & $63.8(60.0-78.0)$ & $39.4(22.5-53.6)$ & $<0.01$ & $88.0(80.7-90.0)$ & $74.6(71.6-78.1)$ & 0.04 \\
\hline HLA-DR \% & $42.0(25.0-56.8)$ & $24.2(18.6-39.1)$ & 0.04 & $39.6(28.4-45.7)$ & $31.2(18.4-44.6)$ & 0.31 \\
\hline
\end{tabular}

Data are presented as median value (interquartile range). Values show per cent CD4+ or CD8+ T-cells expressing the indicated marker. HLA-DR: human leukocyte antigen late activation marker. 
influx of polyclonal T-cells expressing other $\mathrm{T}$-cell receptor variable (TCR V) gene segments.

\section{Discussion}

Since wheat flour is known to be an occupational allergen causing chronic respiratory disorders [1], the authors were interested in understanding what roles different wheat flour components may play in inducing airway inflammatory parameters. In this study, the authors focused on starch, which is one ingredient in wheat flour. Cornstarch glove powder has been shown previously to be able to cause granulomatous inflammation [3, 4]. To investigate any role for cornstarch in affecting airway inflammatory parameters, healthy individuals were exposed to cornstarch glove powder, using a whole-body exposure chamber, which was previously shown to provide a stable wheat aerosol concentration level inside the chamber [2]. Before and after exposure, BAL cell subpopulations were analysed and in particular, using fluorescence-activated cell sorter (FACS), the expression of various activation, adhesion and subset markers on AM and on BAL CD4+ and CD8+ T-cells were investigated.

Dramatic changes in the BAL cell compartments were found after exposure to cornstarch glove powder, with a three-fold increase (median) in the BAL cell concentration. The most intriguing finding, however, was the select accumulation of eosinophilic granulocytes, with increased relative numbers of eosinophils in the BAL cell population in every individual. In fact, after cornstarch glove powder exposure the eosinophils made up $>10 \%$ of all BAL cells in four individuals, and $\sim 30 \%$ in two of these individuals. Furthermore, the significant correlation between relative numbers of eosinophils and ECP suggests that the lung-accumulated eosinophils were activated.

According to the manufacturer, the total cornstarch glove powder consisted of cornstarch and a minor fraction of $\mathrm{MgO}$, while the respirable dust was made up of $\sim 40 \%$ organic (cornstarch) and 60\% inorganic materials (MgO). The described inflammatory findings therefore could possibly be induced by either of these components. Although KUSCHNER et al. [8] used a somewhat different form of exposure compared with this study, using a freshly generated $\mathrm{MgO}$ fume, they found no measurable pulmonary inflammatory response, with similar BAL cell concentrations and cytokine levels before and after $\mathrm{MgO}$ exposure. Also, the presence of $\mathrm{MgO}$ in cornstarch glove powder did not induce any detectable changes when analysing the tissue response to surgical cornstarch glove powder in rats [9]. The authors consequently suggest that the organic fraction of glove powder is the active component to induce the eosinophilic granulocyte accumulation in BAL fluid. In preliminary experiments it was investigated whether cornstarch could affect eosinophil adhesion and/or transmigration, using a newly developed in vitro model [10]. However, in two separate experiments, any influence of cornstarch on either interleukin5-primed or unprimed eosinophils could not be detected. An alternative mechanism may be that cornstarch stimulated the release of chemoattractant factors specific for eosinophils, such as eotaxin [11], leading to a select accumulation of eosinophils in the BAL fluid. Eotaxin levels in BAL fluid, however, were not found to change significantly after exposure.

Markers for monocyte/macrophage differentiation, adhesion and activation were also analysed and it was found that the AM expression of the lipopolysaccharide receptor CD14 was significantly increased after exposure, while CD16 (Fc $\gamma$ RIII) and activation markers HLA class I and class II molecules were significantly decreased. This finding is compatible with an influx to the airways of monocytes, with a higher expression of CD14 and a lower expression of CD16 and HLA class I and II molecules compared with mature AMs [12-14]. In healthy individuals, exposure to cornstarch glove powder thus results in an increased AM concentration in BAL fluid as well as an altered AM phenotype, consistent with an increased proportion of less activated and differentiated monocytic cells.

The BAL T-cell compartment also underwent significant changes after cornstarch glove powder exposure. The most dramatic consequence was the reduced number of CD4+ Tcells expressing the early activation marker CD69, found in every individual. Moreover, the late activation marker HLADR was significantly reduced after exposure, as was the relative number of $\mathrm{C} 57+\mathrm{T}$-cells, while CD28+ BAL CD4+ $\mathrm{T}$-cells increased significantly. The authors have previously described that CD69, HLA-DR and CD57 are expressed in relatively lower numbers and CD28 in relatively higher numbers in peripheral blood compared with BAL fluid CD4+ T-cells in healthy individuals [15]. The described changes after cornstarch glove powder exposure in the BAL CD4+ $\mathrm{T}$-cell compartment are therefore in congruence with an influx of peripheral blood T-cells into the alveoli. In addition, the finding of an essentially similar expression of the three TCR V gene products analysed before and after exposure on BAL and peripheral blood T-cells, is also in line with an influx of a heterogeneous polyclonal T-cell population to the lungs.

Finally, the BAL cell differential counts and FACS analysis were repeated 7-8 months after the cornstarch glove powder exposure in the four individuals with the most pronounced alterations in the eosinophil distributions. At this time point there was a complete normalisation with values close to identical to those obtained before exposure. Also, the FACS analyses suggested a normalisation of the expression of markers on both AM and T-lymphocytes. Thus, the cornstarch glove powder exposure induced only a transiently altered BAL cell composition. Although clinical parameters of bronchoconstriction or other airway symptoms were not monitored, none of the individuals had any subjective complaints of any symptoms at all. This result is in line with a previous report showing no airway reaction after bronchial provocations with nebulised cornstarch powder [6].

In conclusion, a whole-body exposure chamber was used to expose 10 healthy individuals to cornstarch glove powder. Dramatic changes in the bronchoalveolar lavage cell compartment were found, with a three-fold increase in bronchoalveolar lavage cell concentrations. There was a selective accumulation and activation of eosinophilic granulocytes, and an influx of peripheral blood derived monocytes and heterogeneous T-lymphocytes. Although a normalisation was observed, the consequences of repeated exposure cannot be evaluated from this study with a single exposure. Cornstarch glove powder exposure may be an interesting model for future studies of lung-accumulated eosinophil granulocytes in humans.

\footnotetext{
Acknowledgements. The authors would like to thank B. Dahlberg, M. Dahl and G. de Forest for skillful technical assistance, and J. Lundahl for discussions.
}

\section{References}

1. Baur A. Baker's asthma: causes and prevention. Int Arch Occup Environ Health 1999; 72: 292-296.

2. Lidén C, Lundgren L, Skare L, Lidén G, Tornling G, Krantz S. 
A new whole-body exposure chamber for human skin an lung challenge experiments - the generation of wheat flour aerosols. Ann Occup Hyg 1998; 42: 541-547.

3. Berkow A. Surgery. Cornstarch peritonitis following the trail of the surgeon's gloves. Postgrad Med 1976; 59: 231-236.

4. Fujiwara M, Watanabe A, Tsuchiya $\mathrm{T}$, et al. A case of cornstarch granuloma. Jpn J Med 1984; 23: 246-249.

5. Brugnami G, Marabini A, Siracusa A, Abbritti G. Workrelated late asthmatic response induced by latex allergy. J Allergy Clin Immunol 1995; 96: 457-464.

6. Pisati G, Baruffini A, Bernabeo F, Stanizzi R. Bronchial provocation testing in the diagnosis of occupational asthma due to latex surgical gloves. Eur Respir J 1994; 7: 332-336.

7. Eklund A, Blaschke E. Relationship between changed alveolarcapillary permeability and angiotensin converting enzyme activity in serum in sarcoidosis. Thorax 1986; 41: 629-634.

8. Kuschner W, Wong H, D'Alessandro A, Quinlan P, Blanc P. Human pulmonary responses to experimental inhalation of high concentration fine and ultrafine magnesium oxide particles. Environ Health Perspect 1997; 105: 1234-1237.

9. Pelling $\mathrm{D}$, Butterworth $\mathrm{K}$. Influence of the sterilization method and of magnesium oxide on the tissue responses in the rat to modified starch glove powders. J Pharm Pharmacol 1980; 32: 757-760.
10. Moshfehg A, Halldén G, Lundahl J. Methods for simultaneous quantitative analysis of eosiophil and neutrophil adhesion and transmigration. Scand J Immunol 1999; 50: 262-269.

11. Jose P, Griffiths-Johnson A, Collins P, Walsh D, Moqbel R, Totty N. Eotaxin: a potent eosinophil chemoattractant cytokine detected in a guinea pig model of allergic airways inflammation. J Exp Med 1994; 179: 881-887.

12. Prieto J, Eklund A, Patarroyo M. Regulated expression of integrins and other adhesion molecules during differentiation of monocytes into macrophages. J Immunol 1994; 156 : 191-201.

13. Stent $\mathrm{G}$, Irving $\mathrm{L}$, Lewing $\mathrm{S}$, Crowe $\mathrm{A}$. The kinetics of surface expression of CD11/CD18 integrins and CD54 on monocytes and macrophages. Clin Exp Immunol 1995; 100: 366-376.

14. Striz I, Pokorna H, Zheng L, Guzman J, Costabel U. Different expression of integrins by mononuclear phagocytes in peripheral blood and bronchoalveolar lavage fluid. Respir Med 1998; 92: 1326-1330.

15. Katchar K, Wahlström J, Eklund A, Grunewald J. Highly activated $\mathrm{T}$ cell receptor $\mathrm{AV} 2 \mathrm{~S} 3+\mathrm{CD} 4+$ lung $\mathrm{T}$ cell expansions in pulmonary sarcoidosis. Am $J$ Respir Crit Care Med 2001; 163: 1540-1545. 